\title{
TP53 Status and Response to Treatment in Breast Cancers
}

\author{
Mariana Varna, ${ }^{1,2}$ Guilhem Bousquet, ${ }^{1,2}$ Louis-François Plassa, ${ }^{3}$ Philippe Bertheau, ${ }^{1,2,4}$ \\ and Anne Janin ${ }^{1,2,4}$
}

${ }^{1}$ Université Paris Diderot, Sorbonne Paris Cité, Laboratoire de Pathologie, UMR-S 728, 75010 Paris, France

${ }^{2}$ INSERM U728, 75010 Paris, France

${ }^{3}$ AP-HP-Hôpital Saint-Louis, Laboratoire de Biochimie, 75010 Paris, France

${ }^{4}$ AP-HP-Hôpital Saint-Louis, Laboratoire de Pathologie, 75010 Paris, France

Correspondence should be addressed to Mariana Varna, mariannavarna@yahoo.fr

Received 22 October 2010; Revised 8 March 2011; Accepted 24 March 2011

Academic Editor: Paul W. Doetsch

Copyright () 2011 Mariana Varna et al. This is an open access article distributed under the Creative Commons Attribution License, which permits unrestricted use, distribution, and reproduction in any medium, provided the original work is properly cited.

The p53 wild-type protein plays an important role in cells as is shown by its fine regulation at different levels. Since its discovery, numerous mutations have been described. In breast cancers, p53 is mutated in almost 30\% of cases, with a higher frequency in some tumor subtypes. TP53 mutation is reported to be a factor for good prognosis in some studies, while in others it is a factor for poor prognosis. The explanation for these different results could be linked to the fact that the studies were performed on different tumor types and with different therapy regimens.

\section{Introduction}

Breast cancer affects more than one million patients annually in the world and is a leading cause of mortality [1]. The prognosis of patients with localized breast cancer is determined by clinical and biological factors such as age at diagnosis, tumor size, nodal status, tumor histological grading, expression of estrogen/progesterone receptors [2], and Her2 status. Treatments combine surgery on the primary tumor, radiation therapy of the breast, chemotherapy, and hormone therapy.

In adjuvant setting, the benefit of chemotherapy has been confirmed since the 1980 s by the 5-yearly meta-analyses of the Early Breast Cancer Trialists' Collaborative Group (EBCTCG), particularly in women under 50 years [3]. Adjuvant regimens include mainly anthracyclines and taxanes [4]. In patients with localized breast cancer overexpressing Her2, trastuzumab has been proven to significantly increase survival [5]. In patients with estrogen receptor (ER-) positive tumors, addition of hormone therapy such as tamoxifen or aromatase inhibitors significantly decreases the risk of recurrence and increases survival $[3,6]$.

The same chemotherapeutic agents and hormone therapies are currently used for patients with metastatic disease.
Despite a clear benefit of these medical treatments in terms of survival, median overall survival ranges from 31-39 months [7, 8], In addition, $20-40 \%$ patients exhibit primary resistance to medical treatment [7-9] suggesting that we need better knowledge of the predictive factors of response to treatment (chemotherapy, hormone therapy, radiotherapy). In this paper, we review the relationship between TP53 status in breast cancers and response to treatment.

\section{The Biology of TP53}

In 1979, three teams led by A. Levine, P. May and L. Old discovered the $\mathrm{p} 53$ protein, a protein that is, highly conserved across animal species, which is encoded by the TP53 gene located on the short arm of chromosome 17 (17p13.1). Its sequence, about $20 \mathrm{~Kb}$, contains 11 exons, but the first exon does not encode and is located about $10 \mathrm{~Kb}$ from other exons [10]. In 1989, Vogelstein's team discovered that the TP53 gene is inactivated in human cancers [11].

The p53 protein contains 393 amino acids (AA), is divided into regions highly conserved during evolution [12], and its role in numerous regulatory mechanisms has been well established. The protein is composed of: (i) an Nterminal region (AA 1-42), (ii) a region rich in proline 


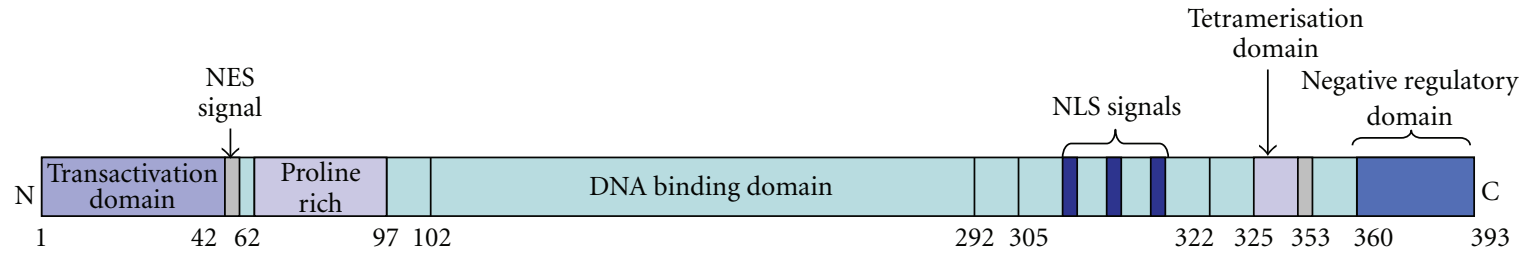

FIgURE 1: The p53 protein structure. The N-terminal region contains the transactivation domain (AA 1-62) and a proline-rich region (residues 63-97) with a role in apoptosis. The central domain (the core domain, AA 102-292) contains specific DNA sites. The C-terminal region includes the tetramerization domain (AA 325-360) and a negative autoregulatory domain. NES signals exist on both N- and Cterminal, whereas NLS signals are located on C-terminal region.

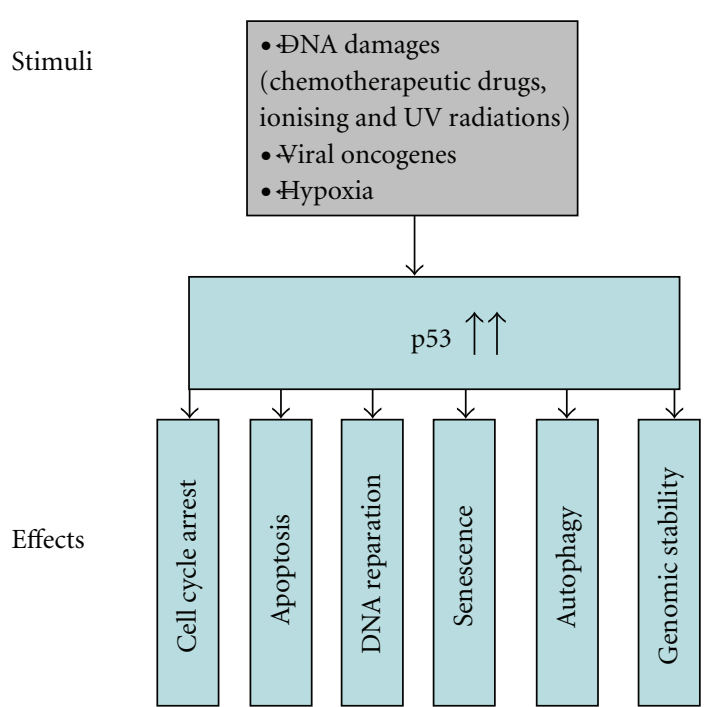

FIGURE 2: Stimuli and effects of activation of p53 protein. In response to diverse stimuli p53 functional protein induces diverse effects such as cell cycle arrest, apoptosis, repair of DNA lesions, senescence, and autophagy.

residues (AA 63-97) involved in the induction of apoptosis [13], (iii) a core domain necessary for binding to DNA (AA 102-292), containing most of the inactivating mutations found in different types of human cancers [14], (iv) a tetramerization domain (AA 323-356), and (v) a C-terminal region (AA 363-393). This C-terminal region of p53 binds to the $\mathrm{N}$-terminal domain of $\mathrm{Mdm} 2$ (murine double minute 2 ). In addition, there are also sequences for exporting to the cytoplasm at the $\mathrm{N}$ - and C-terminal ends (NES, nuclear export signal), as well as nuclear localization sequences at the C-terminal end (NLS, nuclear localization signal), enabling the regulation of subcellular localization of p53 $[15,16]$ (Figure 1).

\section{Stimuli and Activation Effects of TP53}

Multiple stimuli such as ionizing radiations, DNA lesions, nitric oxide, hypoxia, chemotherapeutic agents, or oncogenic stimuli can activate $53[17,18]$ (Figure 2). In response to various stimuli, p53 undergoes different changes and this activation could induce different effects. p53 is a transcription factor involved in the control of $\mathrm{G}_{1} / S$ and $\mathrm{G}_{2} / \mathrm{M}$ phase transition, in DNA repair, and in induction of senescence, apoptosis, autophagy, mitotic catastrophe, and angiogenesis.

3.1. Cell Cycle Regulation. TP53 regulates the control of the $\mathrm{G}_{1}$ checkpoint and can induce an arrest of the cell cycle, repair or apoptosis if DNA lesions are extensive [19]. Wildtype 533 protein can transcriptionally transactivate $p 21^{\text {Cip } 1}$, a potent inhibitor of most cyclin-dependent kinases, involved in the cell cycle arrest [20]. p53 also stimulates the expression of the 14-3-3 $\sigma$ protein that sequesters the cyclin B1/CDK1 complex to block the transition $\mathrm{G}_{2} / \mathrm{M}$. But p53 also induces the expression of many others genes such as GADD45, which interacts with PCNA to inhibit the passage to $S$ phase, or Reprimo to block the cell cycle in $\mathrm{G}_{2}$ phase [21].

3.2. Cell Senescence. Cellular senescence is thought to play an important role in tumor suppression and to contribute to cellular aging [22]. The p53 tumor suppressor is also a critical mediator of senescence, and it seems to play a critical role in the induction and maintenance of cellular senescence. The first information about the importance of p53 on cell senescence was provided by the studies using $\mathrm{T}$ antigens of SV40 virus which inactivate p53. p53-null fibroblasts remain immortal when propagated in vitro. p53 activation is an essential step in the induction of senescence following DNA damage or other forms of stress. In the context of senescence, p53 is controlled by ATM/ATR and Chk1/Chk2 proteins which cause the posttranslational stabilization of p53 through its phosphorylation [23].

3.3. Apoptosis. Apoptosis is one of the principal functions of p53. It has been shown that p53 can transactivate the cell death receptors CD95 or TNF which induce the formation of the DISC complex and finally activate caspase 8. p53 also activates proapoptotic members of the Bcl2 family: Bax, Noxa, and Puma-involved in the permeabilization of the outer mitochondrial membrane [24]. Moreover, p53 has also been reported to have a direct role in cell death initiation by localizing to mitochondria and regulating mitochondrial outer membrane permeabilisation directly. Thus, p53 


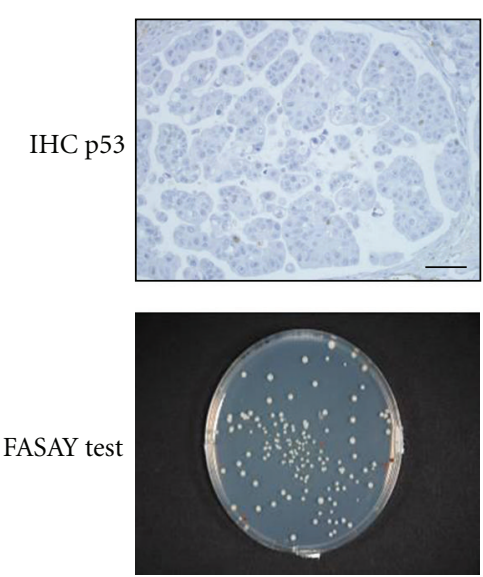

(a)
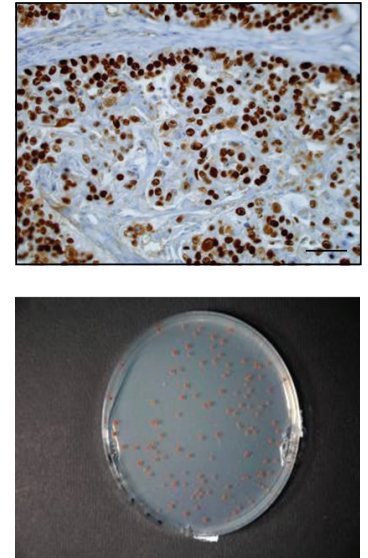

(b)
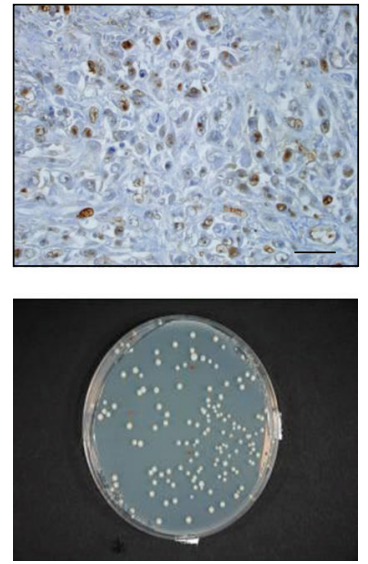

(c)
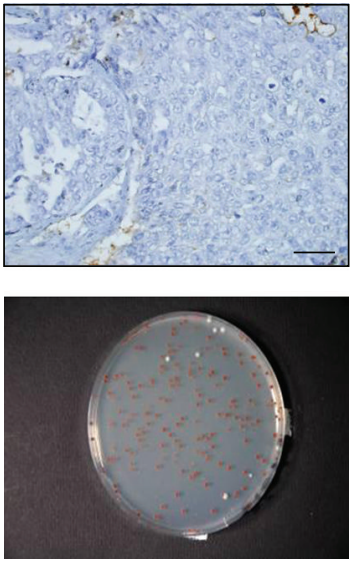

(d)

FIGURE 3: Detection of p53 by immunohystochemistry and determination of TP53 status by FASAY test. Immunohystochemistry (IHC) is not the best method to determine p53 status. Thus, four different situations are illustrated: (a) p53 is negative on IHC and not mutated on FASAY test; (b) p53 is positive on IHC and mutated on FASAY test (red colonies); (c) p53 is weakly positive on IHC but not mutated on FASAY test (white colonies); (d) p53 is negative on IHC but mutated on FASAY test (for exemple codon Stop on exon 5); Magnification x400. p53 antibody (clone DO-7, DakoCytomation, France) was used.

protein can directly induce permeabilisation of the outer mitochondrial membrane by forming complexes with the protective BclXL and Bcl2 proteins, resulting in cytochrome C release $[25,26]$.

3.4. Autophagy. Autophagy is a process suppressing tumor initiation and reducing genomic instability. Autophagy consists in the lysosomal degradation of intracellular components leading to the generation of new metabolic substrates, thus favouring adaptation to stress and cell survival [27]. p53 can activate but also inhibit autophagy. Under stress, p53 can activate its target gene in the nucleus, such as AMPK $\beta 1$ and $\beta 2$ (AMP-activated protein kinase) [28], DAPK-1 (deathassociated protein kinase1), and DRAM (damage-regulated autophagy modulator) [29]. Cytoplasmic, but not nuclear, p53 is able to repress autophagy $[30,31]$.

3.5. Mitotic Catastrophe. Mitotic catastrophe is a biological state that precedes cell death. In response to DNA damage, checkpoints are activated to delay cell cycle progression and to coordinate repair. Reports have suggested that the absence of p53 might increase mitotic catastrophe [32]. p53-deficient cells in an unchecked tetraploid $G_{1}$ state reduplicate their DNA, leading to polyploidy and subsequent chromosomal instability. In the presence of wild-type p53, the polyploidy causes the activation of $\mathrm{p}_{21}{ }^{\mathrm{CIP} 1}$ and an irreversible arrest in the cell cycle, or in cell death, thus preventing the propagation of aneuploidy [33].

3.6. Angiogenesis. The formation of new blood capillaries (angiogenesis) is closely regulated by proangiogenic and antiangiogenic factors [34]. The p53 protein has been shown to limit angiogenesis by few mechanisms: (1) interfering with central regulators of hypoxia that mediate angiogenesis, (2) inhibiting the production of proangiogenic factors, and (3) directly increasing the production of endogenous angiogenesis inhibitors. The combination of these effects allows p53 to efficiently shut down the angiogenic potential of cancer cells [35]. Wild-type p53 plays a role in limiting tumor vascularization as demonstrated by some clinical studies [36]. Mutant p53 plays a central role in promoting angiogenesis in colon cancer progression [37], and tumors carrying p53 mutations are more highly vascularised than tumors harboring wild-type p53. The loss of TP53 appears to amplify the HIF (Hypoxia Inducible Factor) pathway. HIF$1 \alpha$ has been shown to be physically associated with p53 in immuno-precipitation experiments. p53 promotes MDM2mediated ubiquitination and degradation of HIF- $1 \alpha$, while loss of p53 leads to amplification of the HIF response [38].

\section{Regulation of p53}

The protein p53 can be regulated at different levels:

(i) by posttranslational modifications, such as phosphorylation, sumoylation, or acetylation of the protein $[39,40]$,

(ii) by increasing the protein concentration: one of the key regulators of $\mathrm{p} 53$ is $\mathrm{Mdm} 2$ which targets $\mathrm{p} 53$ for breakdown by the proteasome [41],

(iii) by cellular localization: import and nuclear export is closely regulated because the functions of $\mathrm{p} 53$ depend on its nuclear localization. Efficient transfer to the cytoplasm depends on Mdm2 forming a complex with p53, which is why ubiquitin ligase activity of $\mathrm{Mdm} 2$ is essential for nuclear export of p53 [42]. 
The ubiquitinilation of p53 by Mdm2 occurs in the C-terminus domain, and it has been shown that mutations in lysine residues inhibit the nuclear export of p53 by Mdm2 [15].

\section{Detection of p53}

Under normal conditions, $\mathrm{p} 53$ protein remains undetectable due to its short half-life (Figure 3(a)). In contrast, mutant proteins accumulate in the nucleus of tumor cells due to increased half-life and an altered conformational structure (Figure 3(b)).

In a large majority of studies, detection of p53 is highlighted by the protein in the nucleus using immunohistochemistry techniques. This method of detection could give false positive results from stabilization of wild-type p53 proteins due to cellular stress (Figure 3(c)) or could give false negatives due to codon stop, frameshifts, or other destabilizing mutations (Figure 3(d)). Lack of immunostaining for p53 despite mutation of the TP53 gene was particularly seen in tumors harboring nonsense mutations or deletions/splices [43] while other studies have shown that the identification of positivity for $\mathrm{p} 53$ solely detected by immunohistochemistry did not always reflect a p53 mutation [44].

Another way to determine TP53 status is the FASAY test (Functional Analysis of Separated Alleles in Yeast) [45]. After the extraction of mRNA from whole blood or from tissue (normal or tumoral) reverse transcription by RT-PCR is carried out. The DNA binding domain is amplified and the PCR product is cloned by homologous recombination into yeast with a linearized expression plasmid vector carrying the $5^{\prime}$ and $3^{\prime}$ ends of the TP53 open reading frame. The plasmid, thus, has a constitutive expression of human TP53. The yeast contains an open reading frame (ORF) for adenine regulated by a promoter under the control of TP53. The yeasts are selected on a selective medium lacking leucine, but containing adenine. When TP53 is wild-type, a complete metabolism of adenine occurs and the colonies are white. The cells containing mutant TP53 fail to express adenine, and, consequently, the colonies are red because of the accumulation of an intermediate adenine metabolite. These colonies are also smaller than normal because adenine limits growth. Thus, the TP53 status can be easily determined by the color of transfected yeast cells [45].

Some studies analyzed TP53 status in breast tumors using a robust and sensitive approach combining three different methods: p53 immunohistochemistry, FASAY test, and sequencing of the coding sequence. Tumors were considered TP53 mutant when (i) more than $15 \%$ of the yeast colonies were red (ii) analysis using the split versions of the test could identify the defect in the $5^{\prime}$ or $3^{\prime}$ parts of the gene, and (iii) sequence analysis from mutant yeast colonies could identify an unambiguous genetic defect (mutation, deletion, splicing defects) [46]. FASAY provided a major contribution to the analysis by revealing several TP53 mutations not detected by direct sequencing, principally in samples highly contaminated with stromal cells $[47,48]$.

\section{TP53 Mutations}

The function of p53 is altered in nearly $50 \%$ of cancers, p53 being inactivated by mutations in the DNA binding domain or deletion of the carboxy-terminal domain [49]. In other cases, loss of p53 function is related to other mechanisms such as interaction with a viral protein (in lymphoma, hepatocellular carcinoma), multiplication of the MDM2 gene (in sarcomas), and deletion of p14 ${ }^{\mathrm{ARF}}$ gene (in breast or lung tumors) [50].

p53 transcriptional activity is based on the formation of tetramers (dimers of dimers). Mutant proteins may interfere with wild-type p53 by forming hetero-oligomers that are less competent for specific DNA binding [51]. It has been shown that some missense mutations gain oncogenic properties. In the experimental procedure, the authors introduced common TP53 cancer mutations R248W and $\mathrm{R} 273 \mathrm{H}$, into the humanized p53 knock-in allele in mice. They demonstrate that the tumour-suppressor functions of p53 were abolished in p53-mutant mice. Moreover, interchromosomal translocations were observed [52]. Mutants p53, mutants R248W, and R273H interact with Mre11 and inactivate Mre11/ATM-dependent DNA damage responses, leading to chromosomal translocation and defective $\mathrm{G}_{2} / \mathrm{M}$ checkpoint [53]. The analysis of the spectrum of TP53 somatic mutations in human cancers shows an association between exposure to different types of carcinogens and the development of various cancers. TP53 mutations are mostly missense point mutations and are located in $80 \%$ to $90 \%$ of cases in the central region encoding the DNA binding domain $[51,54]$. Some mutations are found much more often than others. Thus, the following six mutations account for about $30 \%$ of all mutations: $175 \mathrm{Arg}-\mathrm{His}$, 248Arg-Gln, 273Arg-His, 248Arg-Trp, 273Cys-Arg and 282Arg-Trp [13].

The universal mutation database (http://www-p53.iarc) contains 30,500 mutations [55]. Thus, mutaions are found in $20-30 \%$ of malignant melanomas [56], in $50 \%$ of superficial bladder cancers, in $29 \%$ of nonsmall cell lung cancers [57], in $58 \%$ of hepatocellular carcinomas [58], and in $25 \%$ of breast cancers [59]. Thirty-seven percent of the myeloma patients with del (17p) present a TP53 mutation versus $0 \%$ of patients lacking the $\operatorname{del}(17 \mathrm{p})$, but the prognostic significance of these mutations remains to be evaluated [60]. The loss of p53 tumor suppressor activity is associated with a poor prognosis in mantle cell lymphoma [61].

\section{TP53 Status and Prognosis in Breast Cancer}

Breast cancer is a heterogeneous disease. Histological type, grade, tumor size, lymph node involvement, and estrogen receptor and HER-2 receptor status, all influence prognosis and the probability of response to systemic therapies [62].

TP53 is mutated in about 30\% of breast cancers [59]. The possible links between alterations of p53 and clinical or pathological features of breast tumors have been widely investigated.

The first study to examine gene-expression patterns of breast cancer suggested that at least four major molecular 
classes of breast cancer exist: luminal-like, basal-like, normallike, and HER-2 positive [63]. Basal-like breast cancers account for $15 \%$ of breast cancers and are often described as triple negative breast cancers (TNBCs). In fact, TNBCs, defined by lack of expression of estrogen receptor, progesterone receptor, and HER2 [64], probably include both basal-like breast cancers and some poorly differentiated luminal breast cancers [65]. They are also associated with a younger age and a poor prognosis [66]. TNBCs also have an increased frequency of TP53 mutations [67]. Recently, it was shown that $\mathrm{p} 53$ status was a strongly unfavorable prognostic factor for relapse-free survival and overall survival only in a triple negative group in patients treated with adjuvant anthracycline-containing chemotherapy. Under this treatment, expression of p53 provides information concerning poor outcome in triple-negative tumors $[67,68]$.

HER2-like tumors show an increased expression of genes associated with ErbB2 amplicon and TP53 mutation [69]. The simultaneous immunodetection of p53/ErbB2 appears to have greater negative prognostic relevance [70]. Other data are consistent with the hypothesis that certain TP53 mutations and ErbB2 overexpression are predictive of resistance to doxorubicin in patients with breast cancer [43].

Inflammatory breast cancer (IBC) is a clinical diagnosis known as the T4d category in the TNM classification [71]. It is a distinct clinical subtype of locally advanced breast cancer (LABC), with a particularly aggressive behaviour and poor prognosis [72]. TP53 mutations are more frequent in inflammatory breast cancer $(50 \%)$ than in noninflammatory breast cancer (20-30\%) [73, 74]. Interpretation of prognostic data is complicated by the fact that earlier studies only used immunohistochemistry to detect the accumulation of p53. Breast tumors with positive immunostaining for $\mathrm{p} 53$ are usually ER and PR negative. This is often associated with a high rate of proliferation, a high histological grade, aneuploidy, and a poor prognosis $[75,76]$. A prognostic value of TP53 mutation by sequencing was found in more than 25 studies analyzing 6000 patients [46]. Moreover, the prognostic significance of TP53 mutation depends on the specificity of the mutation [77].

7.1. p53 Status and Anthracycline Chemotherapy in Breast Cancer. In 50 noninflammatory locally advanced breast cancers that were treated with dose-intense epirubicincyclophosphamide combination, eight complete pathological response (pCR) were shown in the 14 patients with tumors containing mutated TP53, whereas none of the 36 patients with a wild-type TP53 status had a pCR after chemotherapy [78]. In 80 patients with noninflammatory breast cancers treated with front-line chemotherapy comprising epirubicin and cyclophosphamide, 28 had TP53mutant tumors. Fifteen out of these 28 patients exhibited pCR while none of the 52 patients with TP53 wildtype tumors had a pCR. Moreover, nine out of ten of the highly aggressive basal subtypes showed pCRs. This demonstrates that, in noninflammatory breast cancers, TP53 status could be a key predictive factor for response to this chemotherapy treatment and further suggests that the basal subtype is exquisitely sensitive to this association [79]. Research on stage II-III breast cancer patients treated front line with epirubicin-based regimens of various cyclophosphamide dose intensities suggest that cyclophosphamide dose intensification in ER negative and TP53 mutated patients could significantly improve their response [80]. All these studies show an increased response in tumors with a mutation in TP53. Recently, it was shown on in vivo models that epirubicin-cyclophosphamide treatment induces senescence-like features in TP53 wild-type tumor, probably accounting for cell cycle arrest and subsequent resistance to treatment. Conversely in TP53 mutated tumors, chemotherapy induces mitotic catastrophe and tumor death, accounting for complete response to this association exclusively in patients with TP53 mutated tumors [81].

In contrast, in a study on 63 patients with locally advanced breast cancer and treated with doxorubicin, a correlation was observed between the presence of mutations in the zinc finger domain of the $\mathrm{p} 53$ protein and resistance to treatment [82]. These results were confirmed in another study involving 90 patients [43]. Some clinical studies showed that mutant p53 confers chemoresistance in patients with breast cancer. Patients with missense mutations located in zinc-binding regions had significantly decreased disease-free and overall survival relative to patients whose tumors had mutations in other domains [83]. It has been suggested that codon polymorphism 72 (Arg/Pro) could affect the response to chemotherapy in tumor cells through the interaction between p53 and p73 [84]. Protein p73 belongs to the same family as p53 and p63 and shows a striking homology within both the DNA binding domain and oligomerization domain. P73 presents a wide array of splicing variants $\alpha, \beta, \gamma, \delta, \varepsilon, \zeta[85]$. p73 has proapoptotic and antiapoptotic properties. p73alpha mRNAs encode two types of isoform (TAp73alpha and DeltaNp73alpha) resulting from the use of two different promoters, and eliciting or lacking $\mathrm{NH}(2)$-terminal transactivation domain, respectively. DeltaNp73alpha inhibits p53 proapoptotic function [86]. Patients with breast cancer with a variant Pro/Pro TP53 are less sensitive to anthracycline-based therapy than those with a variant Pro/Arg or Arg/Arg [87]. These studies show that mutations in TP53 could induce a resistance to treatment based on anthracyclines.

These results are not contradictory, they rather result from studies exploring different tumor types and different regimens. TP53 status may have a different predictive value for efficacy of anthracycline/alkylating agents-based regimen in each molecular subclass [88]. In 630 patients with breast cancer, the clinical outcome was significantly different for different TP53 mutation types but also for different tumors [89].

7.2. $p 53$ Status and Nonanthracycline Chemotherapy in Breast Cancer. In 67 tumors treated with 5-FU, epirubicin, cyclophosphamide, or paclitaxel, combined sequencing and immunohistochemistry showed a significant association between the presence of TP53 mutation and response to paclitaxel. The efficacy of paclitaxel during mitosis is induced 
by the fact that there is no stop in $G_{1}$ phase, because of absence of p53 [46]. Trastuzumab, an HER2-targeted monoclonal antibody, induces growth arrest and apoptosis in a p53-independent manner. A retrospective study on 104 patients receiving trastuzumab shows that p53 status is not a predictor of the clinical efficacy [90].

Some studies suggested that p53 may influence response to antihormonal treatments. TP53 mutations are less frequent in patients with ER-positive breast cancers, but they are associated with a poorer prognostic in these patients. In vitro studies on human breast cancer cell lines, MN1 (p53WT) and MDD2 (p53MUT) derived from MCF-7, it was shown that p53 mutated cells were more resistant to cytotoxic effects of 4-hydroxy-tamoxifen compared to p53 wild-type cells [91]. Clinical studies on patients with locally advanced breast cancer treated with tamoxifen or primary chemotherapy showed that mutations in the TP53 gene are associated with a poor survival [92]. In a meta-analysis of 4,683 patients with breast cancer, the overexpression of $\mathrm{p} 53$ was correlated with poor outcome in premenopausal women treated with tamoxifen after chemotherapy [93].

7.3. $p 53$ and Radiotherapy. Tumor cell death following exposure to radiotherapy occurs by apoptosis and is a p53-dependent event [94]. Preclinical studies were realized on immunocompromised mice engrafted with fibrosarcoma tumors expressing a functional or TP53-deficient gene. Tumors with functional TP53 contained a large proportion of apoptotic cells and regressed after treatment with gamma radiation or adriamycin. p53-deficient tumors treated with the same regimens continued to enlarge and contained few apoptotic cells. Reduced levels of functional p53 would prevent radiotherapy-induced cell death, while mutant $\mathrm{p} 53$ is a marker for resistance. The defects in apoptosis due to inactivation of $\mathrm{p} 53$ can produce treatment-resistant tumors, suggesting that $\mathrm{p} 53$ status could be important in determining tumor response [95].

In conclusion, TP53 status shows a strong prognosis impact and this could be useful in the choosing the best treatment for breast cancer. Generally, TP53 mutated is associated with a poor response to chemotherapy, hormonotherapy or radiotherapy. Discordant studies concerning its predictive value exist, and this is linked to method of detection of TP53 status. We show that FASAY test and sequencing of TP53 are better than immunohistochemistry to determine if TP53 is mutated or not. Prospective studies using these two methods could better determine its predictive value according to response to treatments.

\section{Acknowledgments}

The authors would like to thank Gabriela Hortopan (University of California, San Francisco, Calif, USA) for helpful comments on the manuscript. Mrs Angela Swaine reviewed the English language. This work was supported by grants from Canceropole Ile de France. M. Varna and G. Bousquet were equally contributed.

\section{References}

[1] A. Stuckey, "Breast cancer: epidemiology and risk factors," Clinical Obstetrics and Gynecology, vol. 54, no. 1, pp. 96-102, 2011.

[2] A. Goldhirsch, J. H. Glick, R. D. Gelher, and H. J. Senn, "Meeting highlights: international consensus panel on the treatment of primary breast cancer," Journal of the National Cancer Institute, vol. 90, no. 21, pp. 1601-1608, 1998.

[3] Early Breast Cancer Trialists' Collaborative Group (EBCTCG), "Effects of chemotherapy and hormonal therapy for early breast cancer on recurrence and 15-year survival: an overview of the randomised trials," The Lancet, vol. 365, no. 9472, pp. 1687-1717, 2005.

[4] M. De Laurentiis, G. Cancello, D. D’Agostino et al., "Taxanebased combinations as adjuvant chemotherapy of early breast cancer: a meta-analysis of randomized trials," Journal of Clinical Oncology, vol. 26, no. 1, pp. 44-53, 2008.

[5] E. H. Romond, E. A. Perez, J. Bryant et al., "Trastuzumab plus adjuvant chemotherapy for operable HER2-positive breast cancer," The New England Journal of Medicine, vol. 353, no. 16, pp. 1673-1684, 2005.

[6] J. Cuzick, I. Sestak, S. E. Pinder et al., "Effect of tamoxifen and radiotherapy in women with locally excised ductal carcinoma in situ: long-term results from the UK/ANZ DCIS trial," The Lancet Oncology, vol. 12, no. 1, pp. 21-29, 2011.

[7] D. W. Miles, A. Chan, L. Y. Dirix et al., "Phase III study of bevacizumab plus docetaxel compared with placebo plus docetaxel for the first-line treatment of human epidermal growth factor receptor 2-negative metastatic breast cancer," Journal of Clinical Oncology, vol. 28, no. 20, pp. 3239-3247, 2010.

[8] M. Andersson, E. Lidbrink, K. Bjerre et al., "Phase III randomized study comparing docetaxel plus trastuzumab with vinorelbine plus trastuzumab as first-line therapy of metastatic or locally advanced human epidermal growth factor receptor 2-positive breast cancer: the HERNATA study," Journal of Clinical Oncology, vol. 29, no. 3, pp. 264-271, 2011.

[9] J. F. Robertson, A. Llombart-Cussac, J. Rolski et al., "Activity of fulvestrant $500 \mathrm{mg}$ versus anastrozole $1 \mathrm{mg}$ as first-line treatment for advanced breast cancer: results from the FIRST study," Journal of Clinical Oncology, vol. 27, no. 27, pp. 45304535, 2009.

[10] M. Lacroix, R. A. Toillon, and G. Leclercq, "p53 and breast cancer, an update," Endocrine-Related Cancer, vol. 13, no. 2, pp. 293-325, 2006.

[11] B. Vogelstein, "Cancer. A deadly inheritance," Nature, vol. 348, no. 6303, pp. 681-682, 1990.

[12] T. Soussi, C. Caron de Fromentel, and P. May, "Structural aspects of the p53 protein in relation to gene evolution," Oncogene, vol. 5, no. 7, pp. 945-952, 1990.

[13] E. A. Slee, D. J. O'Connor, and X. Lu, "To die or not to die: how does p53 decide?” Oncogene, vol. 23, no. 16, pp. 28092818, 2004.

[14] T. Soussi, "The p53 tumor suppressor gene: from molecular biology to clinical investigation," Annals of the New York Academy of Sciences, vol. 910, pp. 121-137, 2000.

[15] M. V. Poyurovsky, C. Katz, O. Laptenko et al., "The C terminus of p53 binds the N-terminal domain of MDM2," Nature Structural \& Molecular Biology, vol. 17, no. 8, pp. 982-989, 2010.

[16] M. A. Lohrum, D. B. Woods, R. L. Ludwig, E. Bálint, and K. H. Vousden, "C-terminal ubiquitination of p53 contributes to 
nuclear export," Molecular and Cellular Biology, vol. 21, no. 24, pp. 8521-8532, 2001.

[17] G. He, Z. H. Siddik, Z. Huang et al., "Induction of $\mathrm{p} 21$ by p53 following DNA damage inhibits both Cdk4 and Cdk2 activities," Oncogene, vol. 24, no. 18, pp. 2929-2943, 2005.

[18] M. L. Cox and D. W. Meek, "Phosphorylation of serine 392 in p53 is a common and integral event during p53 induction by diverse stimuli," Cellular Signalling, vol. 22, no. 3, pp. 564-571, 2010.

[19] L. Wiesmüller, "Genetic stabilization by p53 involves growth regulatory and repair pathways," Journal of Biomedicine \& Biotechnology, vol. 1, no. 1, pp. 7-10, 2001.

[20] M. Ocker and R. Schneider-Stock, "Histone deacetylase inhibitors: signalling towards p21cip1/waf1," The International Journal of Biochemistry \& Cell Biology, vol. 39, no. 7-8, pp. 1367-1374, 2007.

[21] E. S. Helton and X. Chen, "p53 modulation of the DNA damage response," Journal of Cellular Biochemistry, vol. 100, no. 4, pp. 883-896, 2007.

[22] I. Ben-Porath and R. A. Weinberg, "The signals and pathways activating cellular senescence," The International Journal of Biochemistry \& Cell Biology, vol. 37, no. 5, pp. 961-976, 2005.

[23] G. M. Wahl and A. M. Carr, "The evolution of diverse biological responses to DNA damage: insights from yeast and p53," Nature Cell Biology, vol. 3, no. 12, pp. E277-E286, 2001.

[24] K. M. Ryan, "p53 and autophagy in cancer: guardian of the genome meets guardian of the proteome," European Journal of Cancer, vol. 47, no. 1, pp. 44-50, 2011.

[25] M. Mihara, S. Erster, A. Zaika et al., "p53 has a direct apoptogenic role at the mitochondria," Molecular Cell, vol. 11, no. 3, pp. 577-590, 2003.

[26] F. Rodier, J. Campisi, and D. Bhaumik, "Two faces of p53: aging and tumor suppression," Nucleic Acids Research, vol. 35, no. 22, pp. 7475-7484, 2007.

[27] M. C. Maiuri, L. Galluzzi, E. Morselli, O. Kepp, S. A. Malik, and G. Kroemer, "Autophagy regulation by p53," Current Opinion in Cell Biology, vol. 22, no. 2, pp. 181-185, 2010.

[28] A. V. Budanov and M. Karin, "p53 target genes sestrin1 and sestrin2 connect genotoxic stress and mTOR signaling," Cell, vol. 134, no. 3, pp. 451-460, 2008.

[29] D. Crighton, S. Wilkinson, J. O'Prey et al., "DRAM, a p53induced modulator of autophagy, is critical for apoptosis," Cell, vol. 126, no. 1, pp. 121-134, 2006.

[30] E. Tasdemir, M. C. Maiuri, L. Galluzzi et al., "Regulation of autophagy by cytoplasmic p53," Nature Cell Biology, vol. 10, no. 6, pp. 676-687, 2008.

[31] E. Morselli, E. Tasdemir, M. C. Maiuri et al., "Mutant p53 protein localized in the cytoplasm inhibits autophagy," Cell Cycle, vol. 7, no. 19, pp. 3056-3061, 2008.

[32] H. Vakifahmetoglu, M. Olsson, and B. Zhivotovsky, "Death through a tragedy: mitotic catastrophe," Cell Death and Differentiation, vol. 15, no. 7, pp. 1153-1162, 2008.

[33] M. Castedo, J. L. Perfettini, T. Roumier, K. Andreau, R. Medema, and G. Kroemer, "Cell death by mitotic catastrophe: a molecular definition," Oncogene, vol. 23, no. 16, pp. 28252837, 2004.

[34] S. L. Harris and A. J. Levine, "The p53 pathway: positive and negative feedback loops," Oncogene, vol. 24, no. 17, pp. 2899 $2908,2005$.

[35] J. G. Teodoro, S. K. Evans, and M. R. Green, "Inhibition of tumor angiogenesis by p53: a new role for the guardian of the genome," Journal of Molecular Medicine, vol. 85, no. 11, pp. 1175-1186, 2007.
[36] Y. Takahashi, C. D. Bucana, K. R. Cleary, and L. M. Ellis, "p53, vessel count, and vascular endothelial growth factor expression in human colon cancer," International Journal of Cancer, vol. 79, no. 1, pp. 34-38, 1998.

[37] P. Faviana, L. Boldrini, R. Spisni et al., "Neoangiogenesis in colon cancer: correlation between vascular density, vascular endothelial growth factor (VEGF) and p53 protein expression," Oncology Reports, vol. 9, no. 3, pp. 617-620, 2002.

[38] P. H. Maxwell, C. W. Pugh, and P. J. Ratcliffe, "Activation of the HIF pathway in cancer," Current Opinion in Genetics \& Development, vol. 11, no. 3, pp. 293-299, 2001.

[39] X. Q. Wang, E. J. Stanbridge, X. Lao, Q. Cai, S. T. Fan, and J. L. Redpath, "p53-dependent Chk1 phosphorylation is required for maintenance of prolonged G2 arrest," Radiation Research, vol. 168, no. 6, pp. 706-715, 2007.

[40] T. Li, R. Santockyte, R. F. Shen et al., "Expression of SUMO$2 / 3$ induced senescence through p53- and pRB-mediated pathways," The Journal of Biological Chemistry, vol. 281, no. 47, pp. 36221-36227, 2006.

[41] L. E. Giono and J. J. Manfredi, "Mdm2 plays a positive role as an effector of p53-dependent responses," Cell Cycle, vol. 6, no. 17, pp. 2143-2147, 2007.

[42] F. Toledo and G. M. Wahl, "Regulating the p53 pathway: in vitro hypotheses, in vivo veritas," Nature Reviews Cancer, vol. 6, no. 12, pp. 909-923, 2006.

[43] S. Geisler, P. E. Lonning, T. Aas et al., "Influence of TP53 gene alterations and c-erbB-2 expression on the response to treatment with doxorubicin in locally advanced breast cancer," Cancer Research, vol. 61, no. 6, pp. 2505-2512, 2001.

[44] F. C. Schmitt, R. Soares, L. Cirnes, and R. Seruca, "P53 in breast carcinomas: association between presence of mutation and immunohistochemical expression using a semiquantitative approach," Pathology Research and Practice, vol. 194, no. 12, pp. 815-819, 1998.

[45] J. M. Flaman, T. Frebourg, V. Moreau et al., "A simple p53 functional assay for screening cell lines, blood, and tumors," Proceedings of the National Academy of Sciences of the United States of America, vol. 92, no. 9, pp. 3963-3967, 1995.

[46] P. Bertheau, M. Espié, E. Turpin et al., "TP53 status and response to chemotherapy in breast cancer," Pathobiology, vol. 75, no. 2, pp. 132-139, 2008.

[47] M. Varna, H. Soliman, J. P. Feugeas et al., "Changes in allelic imbalances in locally advanced breast cancers after chemotherapy," British Journal of Cancer, vol. 97, no. 8, pp. 1157-1164, 2007.

[48] E. Manie, A. Vincent-Salomon, J. Lehmann-Che et al., "High frequency of TP53 mutation in BRCA1 and sporadic basal-like carcinomas but not in BRCA1 luminal breast tumors," Cancer Research, vol. 69, no. 2, pp. 663-671, 2009.

[49] T. Soussi and K. G. Wiman, "Shaping genetic alterations in human cancer: the p53 mutation paradigm," Cancer Cell, vol. 12, no. 4, pp. 303-312, 2007.

[50] B. Vogelstein, D. Lane, and A. J. Levine, "Surfing the p53 network," Nature, vol. 408, no. 6810, pp. 307-310, 2000.

[51] A. Petitjean, M. I. Achatz, A. L. Borresen-Dale, P. Hainaut, and M. Olivier, "TP53 mutations in human cancers: functional selection and impact on cancer prognosis and outcomes," Oncogene, vol. 26, no. 15, pp. 2157-2165, 2007.

[52] H. Song, M. Hollstein, and Y. Xu, "p53 gain-of-function cancer mutants induce genetic instability by inactivating ATM," Nature Cell Biology, vol. 9, no. 5, pp. 573-580, 2007. 
[53] D. P. Liu, H. Song, and Y. Xu, "A common gain of function of p53 cancer mutants in inducing genetic instability," Oncogene, vol. 29, no. 7, pp. 949-956, 2010.

[54] T. Soussi, B. Asselain, D. Hamroun et al., "Meta-analysis of the p53 mutation database for mutant p53 biological activity reveals a methodologic bias in mutation detection," Clinical Cancer Research, vol. 12, no. 1, pp. 62-69, 2006.

[55] T. Soussi, D. Hamroun, L. Hjortsberg et al., "MUT-TP53 2.0: a novel versatile matrix for statistical analysis of TP53 mutations in human cancer," Human Mutation, vol. 31, no. 9, pp. 1020$1025,2010$.

[56] J. Weiss, M. Heine, K. C. Arden et al., "Mutation and expression of TP53 in malignant melanomas," Recent Results in Cancer Research, vol. 139, pp. 137-154, 1995.

[57] E. Jassem, J. Niklinski, R. Rosell et al., "Types and localisation of p53 gene mutations: a report on 332 non-small cell lung cancer patients," Lung Cancer, vol. 34, 2, pp. S47-S51, 2001.

[58] X. M. Wu, J. G. Fu, W. Z. Ge et al., "Screen p53 mutations in hepatocellular carcinoma by FASAY: a novel splicing mutation," Journal of Zhejiang University. Science B, vol. 8, no. 2, pp. 81-87, 2007.

[59] M. Olivier, A. Langerod, P. Carrieri et al., "The clinical value of somatic TP53 gene mutations in 1,794 patients with breast cancer," Clinical Cancer Research, vol. 12, no. 4, pp. 1157-1167, 2006.

[60] L. Lode, M. Eveillard, V. Trichet et al., "Mutations in TP53 are exclusively associated with del(17p) in multiple myeloma," Haematologica, vol. 95, no. 11, pp. 1973-1976, 2010.

[61] L. Stefancikova, M. Moulis, P. Fabian et al., "Loss of the p53 tumor suppressor activity is associated with negative prognosis of mantle cell lymphoma," International Journal of Oncology, vol. 36, no. 3, pp. 699-706, 2010.

[62] L. Pusztai, C. Mazouni, K. Anderson, Y. Wu, and W. F. Symmans, "Molecular classification of breast cancer: limitations and potential," The Oncologist, vol. 11, no. 8, pp. 868-877, 2006.

[63] C. M. Perou, T. Sorile, M. B. Eisen et al., "Molecular portraits of human breast tumours," Nature, vol. 406, no. 6797, pp. 747752,2000

[64] O. Gluz, C. Liedtke, N. Gottschalk, L. Pusztai, U. Nitz, and N. Harbeck, "Triple-negative breast cancer-current status and future directions," Annals of Oncology, vol. 20, no. 12, pp. 1913-1927, 2009.

[65] F. C. Bidard, R. Conforti, T. Boulet, S. Michiels, S. Delaloge, and F. André, "Does triple-negative phenotype accurately identify basal-like tumour? An immunohistochemical analysis based on 'triple-negative' breast cancers," Annals of Oncology, vol. 18, no. 7, pp. 1285-1286, 2007.

[66] L. A. Carey, C. M. Perou, C. A. Livasy et al., "Race, breast cancer subtypes, and survival in the Carolina Breast Cancer Study," The Journal of the American Medical Association, vol. 295, no. 21, pp. 2492-2502, 2006.

[67] B. J. Chae, J. S. Bae, A. Lee et al., "p53 as a specific prognostic factor in triple-negative breast cancer," Japanese Journal of Clinical Oncology, vol. 39, no. 4, pp. 217-224, 2009.

[68] M. C. Cheang, D. Voduc, C. Bajdik et al., "Basal-like breast cancer defined by five biomarkers has superior prognostic value than triple-negative phenotype," Clinical Cancer Research, vol. 14, no. 5, pp. 1368-1376, 2008.

[69] T. Sorlie, C. M. Perou, R. Tibshirani et al., "Gene expression patterns of breast carcinomas distinguish tumor subclasses with clinical implications," Proceedings of the National Academy of Sciences of the United States of America, vol. 98, no. 19, pp. 10869-10874, 2001.

[70] L. L. Nakopoulou, A. Alexiadou, G. E. Theodoropoulos, A. C. H. Lazaris, A. Tzonou, and A. Keramopoulos, "Prognostic significance of the co-expression of $\mathrm{p} 53$ and c-erbB-2 proteins in breast cancer," The Journal of Pathology, vol. 179, no. 1, pp. 31-38, 1996.

[71] S. E. Singletary, C. Allred, P. Ashley et al., "Revision of the American Joint Committee on cancer staging system for breast cancer," Journal of Clinical Oncology, vol. 20, no. 17, pp. 36283636, 2002.

[72] S. Van Laere, I. Van der Auwera, G. Van den Eynden et al., "Distinct molecular phenotype of inflammatory breast cancer compared to non-inflammatory breast cancer using Affymetrix-based genome-wide gene-expression analysis," The British Journal of Cancer, vol. 97, no. 8, pp. 1165-1174, 2007.

[73] E. Turpin, I. Bièche, P. Bertheau et al., "Increased incidence of ERBB2 overexpression and TP53 mutation in inflammatory breast cancer," Oncogene, vol. 21, no. 49, pp. 7593-7597, 2002.

[74] M. Sawaki, Y. Ito, F. Akiyama et al., "High prevalence of HER2/neu and p53 overexpression in inflammatory breast cancer," Breast Cancer, vol. 13, no. 2, pp. 172-178, 2006.

[75] M. Hensel, A. Schneeweiss, H. P. Sinn et al., "p53 is the strongest predictor of survival in high-risk primary breast cancer patients undergoing high-dose chemotherapy with autologous blood stem cell support," International Journal of Cancer, vol. 100, no. 3, pp. 290-296, 2002.

[76] V. Malamou-Mitsi, H. Gogas, U. Dafni et al., "Evaluation of the prognostic and predictive value of p53 and Bcl-2 in breast cancer patients participating in a randomized study with dosedense sequential adjuvant chemotherapy," Annals of Oncology, vol. 17, no. 10, pp. 1504-1511, 2006.

[77] T. Soussi, "p53 alterations in human cancer: more questions than answers," Oncogene, vol. 26, no. 15, pp. 2145-2156, 2007.

[78] P. Bertheau, F. Plassa, M. Espié et al., "Effect of mutated TP53 on response of advanced breast cancers to high-dose chemotherapy," The Lancet, vol. 360, no. 9336, pp. 852-854, 2002.

[79] P. Bertheau, E. Turpin, D. S. Rickman et al., "Exquisite sensitivity of TP53 mutant and basal breast cancers to a dosedense epirubicin-cyclophosphamide regimen," PLoS Medicine, vol. 4, no. 3, article e90, 2007.

[80] J. Lehmann-Che, F. André, C. Desmedt et al., "Cyclophosphamide dose intensification may circumvent anthracycline resistance of p53 mutant breast cancers," The Oncologist, vol. 15, no. 3, pp. 246-252, 2010.

[81] M. Varna, J. Lehmann-Che, E. Turpin et al., "p53 dependent cell-cycle arrest triggered by chemotherapy in xenografted breast tumors," International Journal of Cancer, vol. 124, no. 4, pp. 991-997, 2009.

[82] T. Aas, A. L. Borresen, S. Geisler et al., "Specific P53 mutations are associated with de novo resistance to doxorubicin in breast cancer patients," Nature Medicine, vol. 2, no. 7, pp. 811-814, 1996.

[83] A. L. Borresen, T. I. Andersen, J. E. Eyfjord et al., “TP53 mutations and breast cancer prognosis: particularly poor survival rates for cases with mutations in the zinc-binding domains," Genes Chromosomes \& Cancer, vol. 14, no. 1, pp. 71-75, 1995.

[84] D. Bergamaschi, M. Gasco, L. Hiller et al., "p53 polymorphism influences response in cancer chemotherapy via modulation of p73-dependent apoptosis," Cancer Cell, vol. 3, no. 4, pp. 387402, 2003.

[85] C. Maisse, P. Guerrieri, and G. Melino, "p73 and p63 protein stability: the way to regulate function?" Biochemical Pharmacology, vol. 66, no. 8, pp. 1555-1561, 2003. 
[86] D. Goldschneider, E. Blanc, G. Raguenez, H. Haddada, J. Bénard, and S. Douc-Rasy, "When p53 needs p73 to be functional-forced p73 expression induces nuclear accumulation of endogenous p53 protein," Cancer Letters, vol. 197, no. 1-2, pp. 99-103, 2003.

[87] Y. Xu, L. Yao, T. Ouyang et al., "p53 codon 72 polymorphism predicts the pathologic response to neoadjuvant chemotherapy in patients with breast cancer," Clinical Cancer Research, vol. 11, no. 20, pp. 7328-7333, 2005.

[88] F. C. Bidard, M. C. Matthieu, P. Chollet et al., "p53 status and efficacy of primary anthracyclines/alkylating agent-based regimen according to breast cancer molecular classes," Annals of Oncology, vol. 19, no. 7, pp. 1261-1265, 2008.

[89] J. Alsner, V. Jensen, M. Kyndi et al., "A comparison between p53 accumulation determined by immunohistochemistry and TP53 mutations as prognostic variables in tumours from breast cancer patients," Acta Oncologica, vol. 47, no. 4, pp. 600607, 2008.

[90] W. J. Kostler, T. Brodowicz, G. Hudelist et al., "The efficacy of trastuzumab in Her-2/neu-overexpressing metastatic breast cancer is independent of p53 status," Journal of Cancer Research and Clinical Oncology, vol. 131, no. 7, pp. 420-428, 2005.

[91] L. Fernandez-Cuesta, S. Anaganti, P. Hainaut, and M. Olivier, "p53 status influences response to tamoxifen but not to fulvestrant in breast cancer cell lines," International Journal of Cancer, vol. 128, no. 8, pp. 1813-1821, 2010.

[92] E. M. Berns, J. A. Foekens, R. Vossen et al., "Complete sequencing of TP53 predicts poor response to systemic therapy of advanced breast cancer," Cancer Research, vol. 60, no. 8, pp. 2155-2162, 2000.

[93] H. S. Kim, C. K. Yom, H. J. Kim et al., "Overexpression of p53 is correlated with poor outcome in premenopausal women with breast cancer treated with tamoxifen after chemotherapy," Breast Cancer Research and Treatment, vol. 121, no. 3, pp. 777-788, 2010.

[94] A. Hamilton and M. Piccart, "The contribution of molecular markers to the prediction of response in the treatment of breast cancer: a review of the literature on HER-2, p53 and BCL-2," Annals of Oncology, vol. 11, no. 6, pp. 647-663, 2000.

[95] S. W. Lowe, S. Bodis, A. McClatchey et al., "p53 status and the efficacy of cancer therapy in vivo," Science, vol. 266, no. 5186, pp. 807-810, 1994. 


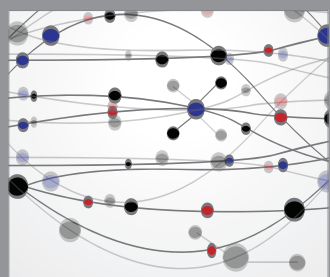

The Scientific World Journal
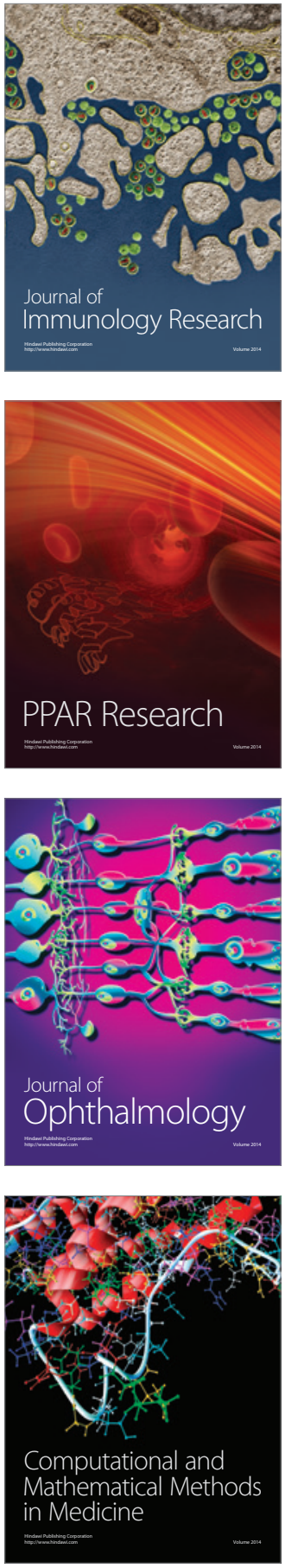

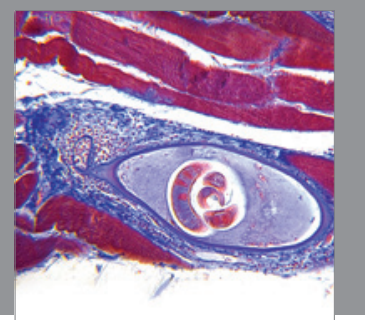

Gastroenterology

Research and Practice
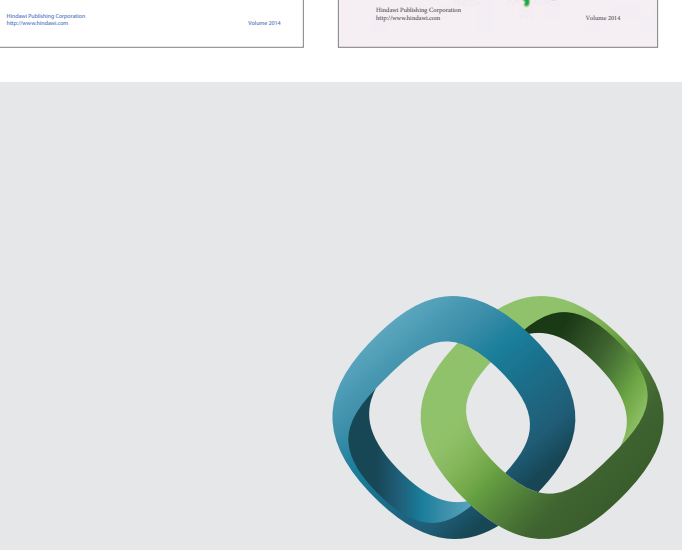

\section{Hindawi}

Submit your manuscripts at

http://www.hindawi.com
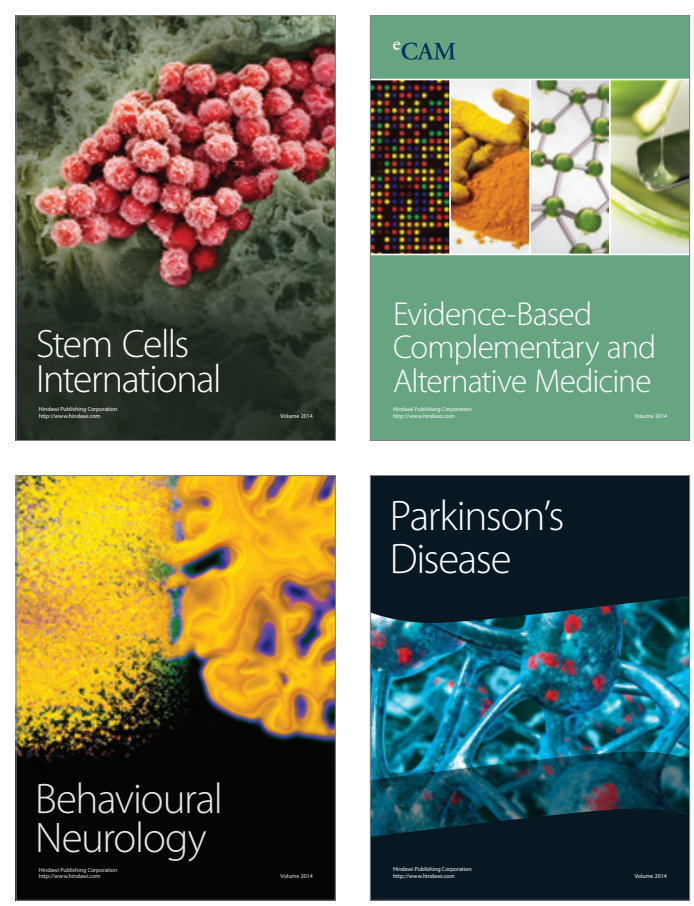

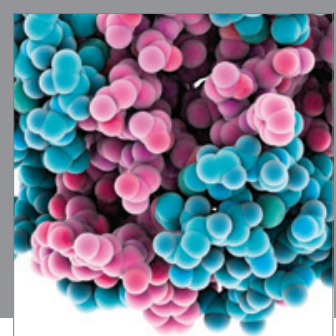

Journal of
Diabetes Research

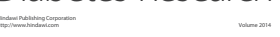

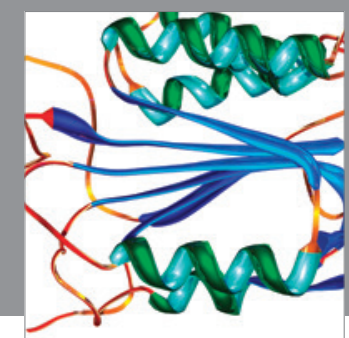

Disease Markers
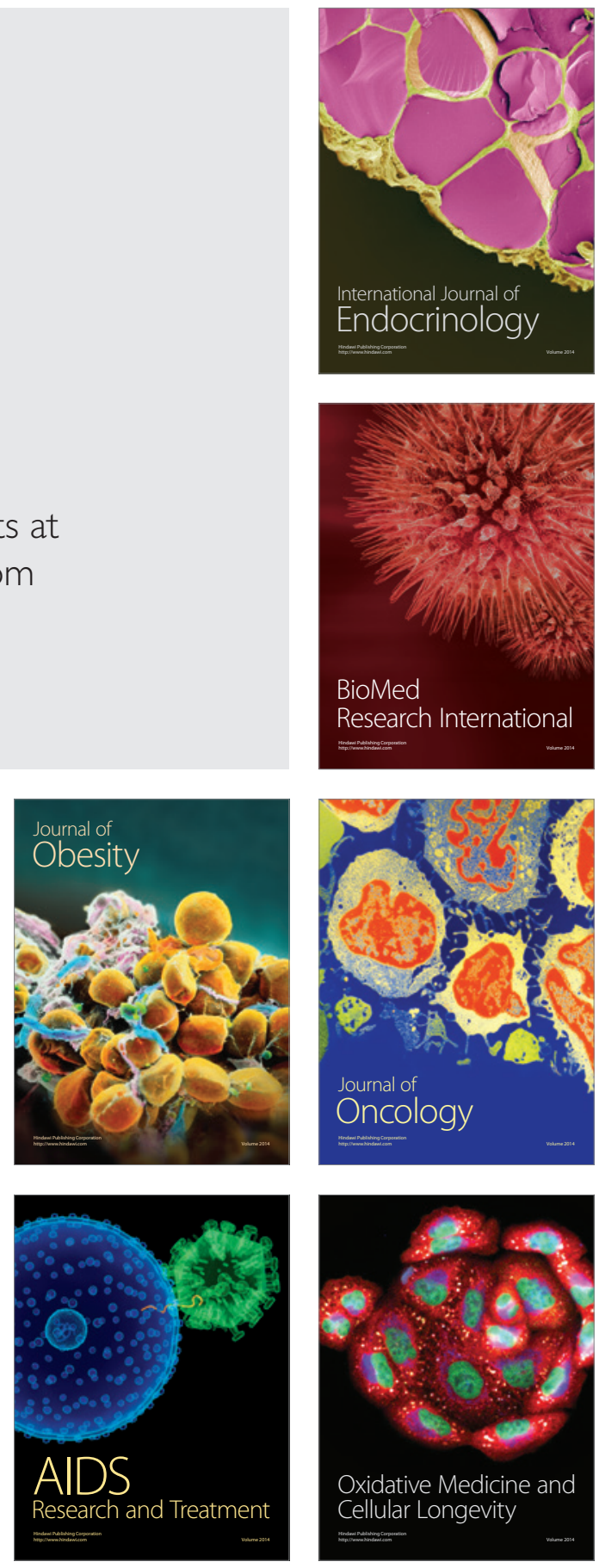